\title{
All the small things: The impact of central venous catheters in neonates undergoing cardiac surgery
}

\author{
Ryan R. Davies, MD
}

\author{
From the Department of Cardiovascular and Thoracic Surgery, UT Southwestern Medical Center and Children's \\ Health, Dallas, Tex. \\ Disclosures: Author has nothing to disclose with regard to commercial support. \\ Received for publication Oct 31, 2017; accepted for publication Nov 8, 2017; available ahead of print Dec 6, 2017 \\ Address for reprints: Ryan R. Davies, MD, 1935 Medical District Dr, MC B3.410, Dallas, TX 75235 (E-mail: \\ ryan.davies@utsouthwestern.edu). \\ J Thorac Cardiovasc Surg 2018;155:1159-60 \\ $0022-5223 / \$ 36.00$ \\ Copyright (C) 2017 by The American Association for Thoracic Surgery \\ https://doi.org/10.1016/j.jtcvs.2017.11.034
}

With improved survival, there is increasing recognition of the long-term neurodevelopmental morbidity associated with neonatal cardiac surgery. ${ }^{1}$ Researchers have identified diverse risk factors for this morbidity. ${ }^{2}$ Unfortunately, many of these risk factors, including fetal physiology and genetics, may be difficult (if not impossible) to modify. It is therefore critical to identify opportunities where interventions or changes in practice may mitigate the risk of neurologic injury.

The study by Claessens and colleagues ${ }^{3}$ in this issue of the Journal may present such an opportunity. Claessens and colleagues ${ }^{3}$ have described a high incidence of cerebral sinovenous thrombosis (CSVT) among neonates undergoing cardiac surgery. Among children with preoperative and postoperative magnetic resonance imaging (MRI), preoperative CSVT was found in $7.5 \%$. Of more concern, nearly $22 \%$ of neonates had a finding of a new CSVT on postoperative imaging. This is significantly higher than in previous studies, including studies that used routine magnetic resonance venography.

There may be multiple reasons for this high rate, but the study identified the presence of a central venous catheter (CVC) as a strong and independent predictor of CSVT. The risk of CSVT was $20 \%$ greater for each day that a CVC was in place. As a with many studies of outcomes after neonatal cardiac surgery, there is the possibility of confounding with other aspects of disease severity and postoperative complexity. Several aspects of the study support the strength of the association, however, including the concordance between the side of the CVC and the thrombosis and the higher risk associated with internal jugular CVC placement. Here, then, is a simple and modifiable risk factor that results in important and frequent morbidity.

Although Claessens and colleagues ${ }^{3}$ focus on avoidance of internal jugular venous CVCs, it remains possible that subclavian placement can also impair venous drainage. Perhaps Claessens and colleagues ${ }^{3}$ should have gone further. Is there any justification for placing a CVC in a neonate undergoing cardiac surgery, given these (and other)

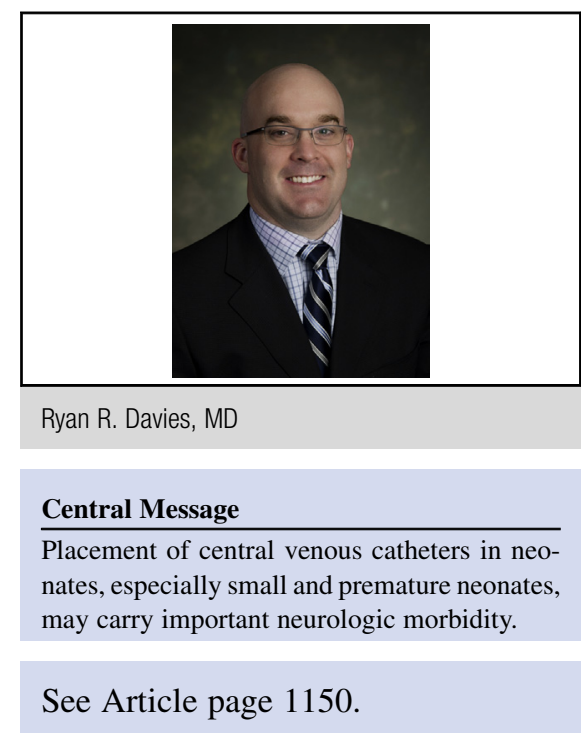

risks? Routine preference for the use of transthoracic intracardiac lines may be the prudent course, especially in the smaller, premature neonates at highest risk. Claessens and colleagues $^{3}$ recommend anticoagulation when a CVC is placed into the internal jugular vein, although, unfortunately, data regarding the utility of anticoagulation for prevention of line-related complications have been poor.

Reassuringly, the neurologic and neurodevelopmental outcomes among patients with findings of CSVT were not different from those without. It is notable, however, that these patients received early diagnosis due to the routine MRI, resulting in early initiation of anticoagulation. This may provide additional support for the routine use of preoperative and postoperative MRI in these high-risk neonates. The acceptable long-term outcomes, however, should not breed complacency regarding the risks of CSVT, which is associated with seizures, strokes, and significant morbidity and mortality.

Although the challenge of the neurologic sequelae of neonatal congenital heart disease and cardiac surgery is complex, it is not intractable. The solution is unlikely to be a single modification of practice or a single treatment strategy, but rather the accumulation of small practice changes, with a resulting gradual improvement in outcomes. Identification of modifiable risk factors is critical to minimizing the risks and optimizing neurodevelopmental outcomes. This study represents an important identification of a problem and includes the seeds of its solution: (1) the avoidance of upper thoracic and cervical CVCs in neonates 
and (2) the use of MRI for early diagnosis and treatment of CSVT.

\section{References}

1. Kaltman JR, Andropoulos DB, Checchia PA, Gaynor JW, Hoffman TM, Laussen PC, et al. Report of the pediatric heart network and national heart, lung, and blood institute working group on the perioperative management of congenital heart disease. Circulation. 2010;121:2766-72.

2. Marino BS, Lipkin PH, Newburger JW, Peacock G, Gerdes M, Gaynor JW, et al; American Heart Association Congenital Heart Defects Committee, Council on Cardiovascular Disease in the Young, Council on Cardiovascular Nursing, and Stroke Council. Neurodevelopmental outcomes in children with congenital heart disease: evaluation and management: a scientific statement from the American Heart Association. Circulation. 2012;126:1143-72.

3. Claessens NH, Algra SO, Jansen NJ, Groenendaal F, de Wit E, Wilbrink AA, et al. Clinical and neuroimaging characteristics of cerebral sinovenous thrombosis in neonates undergoing cardiac surgery. J Thorac Cardiovasc Surg. 2018;155: 1150-8.

4. Andropoulos DB, Hunter JV, Nelson DP, Stayer SA, Stark AR, McKenzie ED, et al. Brain immaturity is associated with brain injury before and after neonatal cardiac surgery with high-flow bypass and cerebral oxygenation monitoring. $J$ Thorac Cardiovasc Surg. 2010;139:543-56.

5. Berfelo FJ, Kersbergen KJ, van Ommen CH, Govaert P, van Straaten HL, PollThe BT, et al. Neonatal cerebral sinovenous thrombosis from symptom to outcome. Stroke. 2010;41:1382-8. 